\title{
Continuous Time Models of Interest Rate: Testing Peso-Dollar Exchange Rate*
}

\author{
José Antonio Núñez** y Elizabeth Ortega***
}

\section{RESUMEN}

Como una extensión del artículo de Núñez, De la Cruz y Ortega (2007), diferentes modelos paramétricos con saltos son probados con la metodología desarrollada por Ait-Sahalia y Peng (2006), basados en la función de transición. Los datos analizados corresponden al tipo de cambio peso-dólar. La idea es implantar modelos paramétricos de tiempo continuo para el tipo de cambio mencionado. Los resultados confirman que los modelos de tiempo continuo propuestos no son suficientemente buenos para explicar el comportamiento del tipo de cambio. Sin embargo, considerando algunos modelos de tiempo continuo con saltos de Poisson, es posible describir tal comportamiento.

Palabras clave: tipo de cambio, saltos, densidad de transición.

Clasificación JEL: G2.

\begin{abstract}
As an extension of the article by Núñez, De la Cruz and Ortega (2007), different parametric models with jumps are tested with the methodology developed by Ait-Sahalia and Peng (2006), based on the transition function. Data analyzed are the peso-dollar exchange rate. The idea is to implement continuous-time parametric models to the pesodollar exchange rate. The results confirm that no continuous time model are not accurate enough to explain the behavior that describes the peso-dollar exchange rate, however, considering some continuous time models with Poisson jumps is possible to describe such behavior.
\end{abstract}

Key words: exchange rate, jumps, transition density.

Clasification JEL: G2

\footnotetext{
* Fecha de recepción: 8 de enero de 2010. Fecha de aceptación: 14 de febrero de 2011.

** Doctor por el Instituto Tecnológico y de Estudios Superiores de Monterrey, México. Correo electrónico: janm@itesm.mx

*** Doctora en Ciencias Financieras por el Instituto Tecnológico y de Estudios Superiores de Monterrey, México. Correo electrónico: ortegabenitez_ely@yahoo.com.mx
} 


\section{INTRODUCTION}

Since December 1994 to date, the peso-dollar exchange rate has been determined by the market under a floating regime forces. The Banco of México (central bank) has refrained from discrete interventions in the foreign exchange market and avoid any type of desired change of signalling. Since the financial crisis of 1994-1995, Mexico exchange rate regime has been gradually each more flexible. Thus, the exchange rate is allowed to fluctuate a growing, with a fixed floor band and an upward crawling ceiling. In addition, have taken some initial steps to promote the development of an institutional framework that would support greater exchange rate flexibility. During this time interval, the exchange rate has suffered serious crisis, from both of the domestic economy (the crisis of 1995) and the rest of the world (crisis in Asia, Russia, 11 September 2001, the Iraqi war, September 2008). The exchange rate flexibility has helped soften the effects of these crises. However, major support from the exchange rate derives from the perceived sound macroeconomic Mexico bases and commitment of financial authorities to avoid occasional interventions.

Recently several authors have developed methodologies for estimating the interest rate structure as models as Nelson and Siegel (1987) and Svensson (1994). These models presume the existence and stability in the data, but you can use these models to explain the exchange rate even though the information available is insufficient or does not have the quality to estimate an approximation. So, it requires a methodology that is able not only to make a reliable estimate of how changing the structure of interest rates over time, but also extract information needed to operate it from the market observations.

This work stems from the idea of giving a contribution in the area of estimation of exchange rate in Mexico, is to test, validate or reject the application of models in continuous time, through a comparison with a series of observed data.

In this paper, a characterization of the process

$$
d X_{t}-\mu\left(X_{t}\right) d t+\sigma\left(X_{t}\right) d W_{t}
$$

where $X_{t}$ is the state variable and $\left\{W_{t}, t \geq 0\right\}$ is a standard Brownian motion. The functions $\mu\left(X_{t}\right)$ and $\sigma^{2}\left(X_{t}\right)$ are respectively the drift and diffusion function of the process, they sometimes are parameterized. 


$$
\mu(X)=\mu(X, \theta) \text { y } \sigma^{2}(X)=\sigma^{2}(X, \theta), \text { where } \theta \in \Theta \subset R^{K}
$$

Any parameterization $\mu\left(X_{t}\right)$ and $\sigma^{2}\left(X_{t}\right)$ correspond to a parameterization of the marginal density. The basic idea is to use the mapping between the drift and diffusion against marginal density to test the model specification.

There is an exhaustive list of proposed models of continuous time dynamics for the short rate, to discriminate between these models, we focus on the following question, when a parametric model is an appropriate to describe the movements of exchange rate? As Núñez (2007), we will use the null hypothesis, which given a parametric model, thus established that there are parametric values for which the parametric model under consideration is an acceptable representation of data. The alternative hypothesis, however, says that no parameter value is capable of reproducing the exact functions.

The next table 1 shows the list of models considered in this work:

Table 1

\begin{tabular}{|l|l|l|}
\hline Parametric model & $\mu(X, \theta)$ & $\sigma(X, \theta)$ \\
\hline Vasicek (1977) & $\alpha_{0}+\alpha_{1} X$ & $\beta_{0}$ \\
\hline $\begin{array}{l}\text { Cox, Ingersoll \& Ross } \\
\text { (1985) }\end{array}$ & $\alpha_{0}+\alpha_{1} X$ & $\beta_{1} \sqrt{X}$ \\
\hline CIR VR & - & $\beta_{1} X^{3 / 2}$ \\
\hline $\begin{array}{l}\text { Brennan \& Schwartz } \\
\text { (1979) }\end{array}$ & $\alpha_{0}+\alpha_{1} X$ & $\beta_{2} X$ \\
\hline $\begin{array}{l}\text { Brennan \& Schwartz } \\
\text { (1982) }\end{array}$ & $\alpha_{0}+\alpha_{1} X$ & $\beta_{1} X^{3 / 2}$ \\
\hline Chan (1992) & $\alpha_{0}+\alpha_{1} X$ & $\beta_{2} X^{\beta_{3}}$ \\
\hline General Drift & $\alpha_{0}+\alpha_{1} X X+\alpha_{2} X^{2}+\alpha_{3} / X$ & $\beta_{0}+\beta_{1} X+\beta_{2} X^{\beta_{3}}$ \\
\hline Merton (1973) & $\alpha_{0}$ & $\beta_{0}$ \\
\hline Dothan (1978) & - & $\beta_{1} X$ \\
\hline $\begin{array}{l}\text { Geometric Brownian } \\
\text { Motion (GBM) }\end{array}$ & $\alpha_{1} X$ & $\beta_{1} X$ \\
\hline $\begin{array}{l}\text { Constant Elasticity } \\
\text { Variance (CEV) }\end{array}$ & $\alpha_{1} X$ & $\beta_{2} X^{\gamma}$ \\
\hline
\end{tabular}


In other words, the test statistic is to compare the density implied by the parametric model and the nonparametric estimator, even if the parametric model is not well specified. Thus, the parametric density estimators and non-parametric be close if the parametric model is well specified. This is when you have to introduce a measure for comparison, which we denote as will measure the distance between the two densities will be estimated and given by the following equation:

$$
M \equiv \min _{\theta \in \Theta} \int_{\underline{x}}^{\bar{s}}\left(\pi(X, \theta)-\pi_{0}(X)\right)^{2} \pi_{0}(X) d u .
$$

The statistical test is rejected when the value is large enough. The stationary of the marginal density of the process does not show all available information in the data. For the test, a rejection on the marginal density is when $M$ it is very large, which invalidates the parametric vector function of the drift and diffusion.

The second part of the analysis is based on adding a jump diffusion process to the model shown in Table 1. Thus is because a diffusion process with jumps can be approximated better data generator, the model jumps can have a major impact on short periods of time. Jumping explicit models to improve our understanding phenomena such as "rare events".

Usually the distribution function for these cases is not normal, the crest of the empirical distribution with these events is higher than the normal distribution, implying that the empirical distribution tails are heavier, i.e. it has a greater probability of extreme values compared with the normal distribution.

For these cases the function to be obtained in each of the parametric models of interest rates is the transition probability function, which will apply the statistic suggested by Ait Sahalia (1996) as follows:

$$
M \equiv \min _{\theta \in \Theta} E\left[p(X, \theta)-p_{0}(X)\right]^{2} .
$$

in this case, measure the distance between two probability functions.

\section{NON-PARAMETRIC MODEL}

To do this test using the Generalized Method of Moments for the non-parametric model, and through the first two moments and using the Gaussian kernel can be obtained by approximating the marginal density function. The advantage of using 
this technique is that the distribution of changes in interest rates does not necessarily have to be normal.

The data used to form density estimators consist of discrete observations of the exchange rate daily. This data is used to estimate the density of the process continues without replacing the continuous time model. The asymptotic properties of estimators are derived for a given period. To obtain the marginal density function for the non-parametric model was used the following function:

$$
\hat{\pi}_{0}(u) \equiv \frac{1}{n} \sum_{i=1}^{n} \frac{1}{h_{n}} K\left(\frac{u-r_{i}}{h_{n}}\right) .
$$

where $K(\cdot)$ is the kernel function and $h_{n}$ the bandwidth. In addition, the following estimators are calculated by:

$$
\begin{aligned}
& \hat{E}_{M} \equiv\left(\int_{-\infty}^{+\infty} K^{2}(x) d x\right)\left(\frac{1}{n} \sum_{i=1}^{n} \hat{\pi}_{0}\left(r_{i}\right)\right), \\
& \hat{V}_{M} \equiv\left(\int_{-\infty}^{+\infty}\left\{\int_{-\infty}^{+\infty} K(u) K(u+x) d u\right\}^{2} d x\right)\left(\frac{1}{n} \sum_{i=1}^{n} \hat{\pi}_{0}^{3}\left(r_{i}\right)\right)
\end{aligned}
$$

Any other consistent $E_{M}$ and $V_{M}$ estimators can be used. As you get $z_{1-\alpha}=1.64$ and the 95 percent confidence level. For the Gaussian kernel function is given by:

$$
K(u)=\frac{1}{\sqrt{2 \pi}} \exp \left(-\frac{1}{2} u^{2}\right)
$$

The two constants of this kernel function satisfy:

$$
\begin{aligned}
& \text { - } \int_{-\infty}^{+\infty} K^{2}(x) d x=\frac{1}{2 \sqrt{\pi}} \\
& \text { - } \int_{-\infty}^{+\infty}\left(\int_{-\infty}^{+\infty} K(u) K(u+x) d u\right)^{2} d x=\frac{1}{2 \sqrt{2 \pi}} .
\end{aligned}
$$

And the bandwidth is given by $h_{n}=c_{n} n^{-1 / 4.5}$ where $c_{n}=c$ times the standard deviation of the time series of spot interest rate divided by. Where is chosen by minimizing the mean integrated square error of the estimator. 


\section{PARAMetric Models}

It considers the interest rate models with univariate distribution functions, strictly stationary and have the Markov property. In general, these models follow the following process:

$$
d X_{t}=\mu\left(X_{t}, \theta\right) d t+\sigma\left(X_{t}, \theta\right) d W_{t}
$$

where $X_{t}$ is the state variable and $\left\{W_{t}, t \geq 0\right\}$ is a standard Brownian motion. The functions $\mu\left(X_{t}\right)$ and $\sigma^{2}\left(X_{t}\right)$ are respectively the drift and diffusion function of the process, they sometimes are parameterized.

$$
\mu(X)=\mu(X, \theta) \quad \text { y } \sigma^{2}(X)=\sigma^{2}(X, \theta) \text {, where } \theta \in \Theta \subset R^{K} .
$$

Any parameterization $\mu\left(X_{t}\right)$ and $\sigma^{2}\left(X_{t}\right)$ correspond to a parameterization of the marginal density. We are working with the joint parametric family

$$
P=\left\{\left(\mu(\cdot ; \theta), \sigma^{2}(\cdot ; \theta)\right) \mid \theta \in \Theta\right\},
$$

where $\Theta$ is a compact subset of $\mathcal{R}^{k}$. The null and alternative hypothesis are written as:

$$
\left\{\begin{array}{l}
H_{0}: \exists \theta_{0} \in \Theta \mid \mu(\cdot, \theta)=\mu_{0}, \sigma^{2}(\cdot, \theta)=\sigma_{0}^{2} \\
H_{1}:\left(\mu_{0}(\cdot), \sigma_{0}^{2}(\cdot)\right) \notin P
\end{array}\right\},
$$

where $P$ is described by (6). And more generally given $\mu(\cdot, \theta)$ and $\sigma(\cdot, \theta)$ in $P$, there is a correspondence with a parameterization of the marginal and transitional densities:

$$
\Pi=\left\{(\pi(\cdot, \theta), p(\cdot, \cdot, \cdot, \theta)) \mid\left(\pi(\cdot, \theta), \sigma^{2}(\cdot, \cdot \cdot, ; \theta)\right) \in P, \theta \in \Theta\right\},
$$

where $\pi(x, \theta)$ is the marginal density at $x$ and $p(s, y \mid t, x, \theta)$ is the transition probability density from $x$ at time $t$ to $y$ at time $s$. The estimation of the densities explicitly takes into account the discreteness of the data. The marginal density corresponding to the pair $\left(\mu, \sigma^{2}\right)$ is given by:

$$
\tau(x, \theta)=\frac{\xi(\theta)}{\sigma^{2}(x, \theta)} \exp \left\{\int_{x_{0}}^{x_{1}} \frac{2 \mu(u, \theta)}{\sigma^{2}(u, \theta)} \mathrm{d} u\right\},
$$


where $\varepsilon(\theta)$ it serves to ensure that the integral of the density function is 1 . Equation (7) is obtained from "forward Kolmogorov equation". The density (7) is used for each parametric model, and depending on the expression we have to use a particular method of integration.

Let the true marginal density of the process be $\pi_{0}(x, \theta)=\frac{\xi_{0}}{\sigma_{0}^{2}} \exp \left\{\int_{x_{0}}^{x_{x}} \frac{2 \mu_{0}(u)}{\sigma_{0}^{2}(u)} d u\right\}$ and the space of possible density functions corresponding to the pairs $\left(\mu, \sigma^{2}\right)$ in $P$ is:

$$
\Pi_{M}=\left\{\pi(\cdot, \theta) \mid\left(\mu(\cdot, \theta), \sigma^{2}(\cdot, \theta)\right) \in P, \theta \in \Theta\right\} .
$$

Therefore the null and alternative hypotheses are:

$$
\begin{aligned}
& H_{M 0}: \exists \theta_{0} \in \Theta \mid \pi(\cdot, \theta)=\pi_{0}(\cdot) \\
& H_{M 1}: \pi_{0}(\cdot) \notin \Pi_{M} .
\end{aligned}
$$

It is necessary that $H_{M 0}$ is true to ensure that $H_{0}$ is true. If the density function $\pi_{0}($.$) were known, is easily verify the conjecture with the density of the$ parametric model. But when is unknown, can be estimated, and thus make a statistical test to test the null hypothesis.

Whether or not the parametric model is correctly specified, a non-parametric estimator of the density will converge to the true density. The parametric model of the density will converge to the true density only if it is correctly specified. Ait-Sahalia (1996a) proposed a measure of the distance $M$ between the two densities estimates, where the null hypothesis to be tested is that the parametric specification is correct. The proposed statistic is:

$$
\hat{M} \equiv n b_{n} \min _{\theta \in \Theta} \frac{1}{n} \sum_{i=1}^{n}\left(\pi\left(r_{i}, \theta\right)-\hat{\pi}_{0}\left(r_{i},\right)\right)^{2} .
$$

The non-parametric estimator is calculated using the kernel estimator of the marginal density:

$$
\hat{\pi}_{0}\left(r_{i}\right) \equiv \frac{1}{n} \sum_{i=0}^{n} \frac{1}{b_{n}} K\left(\frac{u-r_{i}}{b_{n}}\right) .
$$


And the distributions of the parameters are:

$$
\begin{aligned}
& n^{1 / 2}\left\{\hat{\theta}_{M}-\theta_{0}\right\}^{d} \rightarrow N\left(0, \Omega_{M}\right) \\
& h_{n}^{-1 / 2}\left\{\hat{M}-E_{M}\right\}^{d} \rightarrow N\left(0, V_{M}\right)
\end{aligned}
$$

where:

$$
\begin{aligned}
& \Omega_{M} \equiv \operatorname{var}\left(\varphi[F]\left(x_{t}\right)\right) \\
& +\sum_{k=i}^{+\infty}\left\{\operatorname{cov}\left(\varphi[F]\left(x_{t}\right), \varphi[F]\left(x_{t+k}\right)\right)+\operatorname{cov}\left(\varphi[F]\left(x_{t+k}\right), \varphi[F]\left(x_{t}\right)\right)\right\}
\end{aligned}
$$

where $F_{0}($.$) denotes the cumulative density function associated with density$ $\pi_{0}(.) ; \varphi\left(F_{0}\right)$ is the derivative of the functional $\Theta_{M}($.$) is given by:$

$$
\Theta_{M}[F] \equiv \underset{\theta \in \Theta}{\arg \min } \int_{\underline{x}}^{\bar{x}}\left(\pi(x, \theta)-\pi_{0}(x)\right)^{2} \pi_{0}(x) d x .
$$

The test statistic $\hat{M}$ is distributed as:

$$
\text { reject } H_{0} \text { when } \hat{M} \geq \hat{c}(\alpha)=\hat{E}_{M}+\frac{h_{n}^{1 / 2} z_{1-\alpha}}{\hat{V}_{M}^{1 / 2}}
$$

with:

$$
\begin{aligned}
& \hat{E}_{M} \equiv\left(\int_{-\infty}^{+\infty} K^{2}(x) d x\right)\left(\frac{1}{n} \sum_{i=1}^{n} \hat{\pi}_{0}\left(r_{i}\right)\right) \\
& \hat{V}_{M} \equiv 2\left\{\int_{-\infty}^{+\infty}\left(\int_{-\infty}^{+\infty} K(u) K(u+x) d u\right)^{2} \mathrm{~d} x\right\}\left(\frac{1}{n} \sum_{i=1}^{n} \hat{\pi}_{0}^{3}\left(r_{i}\right)\right)
\end{aligned}
$$

and $\Omega_{M}$ given in Ait-Sahalia (1996a, p. 421), and we use the Gaussian kernel:

$$
K(u)=\frac{1}{\sqrt{2 \pi}} \exp \left(-\frac{u^{2}}{2}\right)
$$

Thus values are obtained $M$, if $M$ is large means that the model used does not reflect the behavior of observed data. In any form seeks the minimum value: 
Making the appropriate calculations, include the following marginal density functions for each of the models of interest rate that was obtained. The results are presented in Table 2.

Table 2

\begin{tabular}{|c|c|}
\hline $\begin{array}{l}\text { Parametric } \\
\text { model }\end{array}$ & $\begin{array}{l}\text { Marginal density function } \\
\qquad \pi(x, \theta)\end{array}$ \\
\hline Vasicek (1977) & $\frac{\varepsilon(\theta)}{\beta_{0}} \exp \left\{\frac{2 \alpha_{0}}{\beta_{0}} x+\frac{\alpha_{1}}{\beta_{0}} x^{2}\right\}$ \\
\hline $\begin{array}{l}\text { CIR - Cox, } \\
\text { Ingersoll } \\
\text { \& Ross (1985) }\end{array}$ & $\frac{\varepsilon \theta}{\beta_{2} \cdot x^{1 / 2}} \cdot \exp \left\{\frac{4 \alpha_{0}}{\beta_{1}} x^{1 / 2}+\frac{4 \alpha_{1}}{3 \beta_{1}} x^{3 / 2}\right\}$ \\
\hline CIR VR & $\frac{\varepsilon(\theta)}{\beta} x^{-3 / 2}$ \\
\hline $\begin{array}{l}\text { Brennan \& } \\
\text { Schwartz (1979) }\end{array}$ & $\frac{\varepsilon(\theta)}{\beta_{2} \cdot x_{0}^{2 \alpha_{1} / \beta_{2}}} \cdot x^{\left(\frac{2 \alpha_{1}}{\beta_{2}}-2\right)} \cdot \exp \left\{\frac{2 \alpha_{0}}{\beta_{2} \cdot x_{0}}-\frac{2 \alpha_{0}}{\beta_{2} \cdot x}\right\}$ \\
\hline $\begin{array}{l}\text { Brennan \& } \\
\text { Schwartz (1982) }\end{array}$ & $\frac{\varepsilon(\theta)}{\beta_{1} \cdot x^{3 / 2}} \cdot \exp \left\{\frac{4 \alpha_{1}}{\beta_{1}} x^{1 / 2}-\frac{4 \alpha_{0}}{\beta_{1}} x^{-1 / 2}\right\}$ \\
\hline Chan (1992) & $\frac{\varepsilon(\theta)}{\beta_{2} \cdot x^{\beta_{3}}} \cdot \exp \left\{\frac{2}{\beta_{2}} \cdot x^{-\beta_{3}} \cdot\left(\frac{\alpha_{0} \cdot x}{1-\beta_{3}}+\frac{\alpha_{1} \cdot x^{2}}{2-\beta_{2}}\right)\right\}$ \\
\hline General Drift & $\frac{\varepsilon(\theta)}{\beta_{2} \cdot x^{\beta_{3}}} \cdot \exp \left\{\frac{2}{\beta_{2}} \cdot x^{-\beta_{3}} \cdot\left(\frac{\alpha_{0} \cdot x}{1-\beta_{3}}+\frac{\alpha_{1} \cdot x^{2}}{2-\beta_{3}}+\frac{\alpha_{2} \cdot x^{3}}{3-\beta_{3}}-\frac{\alpha_{3}}{\beta_{3}}\right)\right\}$ \\
\hline Merton (1973) & $\frac{\varepsilon(\theta)}{\beta_{0}} \exp \left\{\frac{2 \alpha_{0}}{\beta_{0}} x\right\}$ \\
\hline Dothan (1978) & $\frac{\varepsilon(\theta)}{\beta_{1}} x^{-1}$ \\
\hline $\begin{array}{l}\text { Geometric Brownian } \\
\text { Motion (GBM) }\end{array}$ & $\frac{\varepsilon(\theta)}{\beta_{1}} x^{-1} \cdot \exp \left\{\frac{2 \alpha_{1}}{\beta^{1}} x\right\}$ \\
\hline $\begin{array}{l}\text { Constant Elasticity } \\
\text { Variance (CEV) }\end{array}$ & $\frac{\varepsilon(\theta)}{\beta^{1}} x^{-\gamma} \cdot \exp \left\{\frac{2 \alpha_{1}}{\beta_{1} \cdot(2-\gamma)} x\right\}$ \\
\hline
\end{tabular}


Then compute the value $\varepsilon(\theta)$ for each of the models, this value depends on the model parameters $\theta=\left(\alpha_{0}, \alpha_{1}, \alpha_{2}, \alpha_{3}, \beta_{0}, \beta_{1}, \beta_{2}, \beta_{3}\right)$.

\section{TRANSITION DENSITY PARAMETRIC MODELS WITH JUMPS}

For the second part of the analysis, is considered a jump diffusion process $X_{t}$ defined on a probability space $\left(\Omega, \mathfrak{I},\left(\mathfrak{I}_{t}\right)_{t \in[0, T]}, \wp\right)$ with filtration $\left\{\mathfrak{I}_{t}\right\}$ satisfying the usual conditions:

$$
d X_{t}=\mu\left(X_{t}, \theta\right) d t+\sigma\left(X_{t}, \theta\right) d W_{t}+J_{t} d N_{t}
$$

Where:

- $\left\{W_{t}, t \geq 0\right\}$ is a standard Brownian motion.

- $\theta \in \mathfrak{R}^{p}$ is a finite vector of parameters to be estimated.

- $\mu\left(X_{t}, \theta\right): \Re^{n} \rightarrow \Re^{n}$ is the function of drift.

- $\sigma^{2}\left(X_{t}, \theta\right): \Re^{n} \rightarrow \Re^{n \times d}$ is the function of dissemination of the process.

- The pure jump process $N$ has a stochastic intensity $\lambda\left(X_{t}, \theta\right)$ and jump size of 1 .

- The jump in size $J_{t}$ is independent $\mathfrak{I}_{t-}$ and has a probability density $v(\cdot, \theta): \Re^{n} \rightarrow \Re$. In our case $v(\cdot, \theta)$ it is normal.

For models with Poisson jumps denote the conditional density $X_{t+\Delta}=y$ given $X_{t}=x$, by $p(\Delta, y \mid x, \theta)$ and is also known as the transition probability density.

$X_{t}$ is a Markov process in continuous time, i.e. a diffusion process with jumps in state space $\Theta$. The distribution function of transition probability is given by:

$$
p(\Delta, y \mid x, \theta)=\operatorname{Pr}\left\{X_{t}<x \mid X_{t 0}=x_{0}\right\},
$$

where $t>t_{0}, X_{t}<x$ means $X_{i t}<x_{i}$ for $i=1: n$.

The assumptions of the model are the following:

Assumption 1. The variance matrix $V(x)$ is positive definite for all $x$ in the domain of the process $X$. 
Assumption 2. The stochastic differential equation (10) has a unique solution. The transition density $p(\Delta, y \mid x, \theta)$ is continuously differentiable with respect to $\Delta$, twice differentiable with respect to $x$ and $y$.

Assumption 3. The boundary of the process $X$ is unattainable.

Assumption 4. $v(),. \mu(),. \sigma($.$) and \lambda($.$) are infinitely differentiable almost every-$ where in the domain of $X$.

Proposition 1. Under assumption 2, the transition density satisfies the backward and forward Kolmogorov equations given by:

$$
\begin{aligned}
\frac{\partial p(\Delta, y \mid x)}{\partial t} & =\frac{1}{2} \frac{\partial^{2}}{\partial y^{2}}\left[\sigma^{2}(y) p(\Delta, y \mid x)\right]-\frac{\partial}{\partial t}[\mu(y) p(\Delta, y \mid x)] \\
& +\int[\lambda(y-c) p(\Delta, y-c \mid x)-\lambda(y) p(\Delta, y \mid x)] v(c) d c
\end{aligned}
$$

Then, $v(\cdot), \mu(\cdot), \sigma(\cdot)$ and $\lambda(\cdot)$ are infinitely differentiable at least anywhere in the domain of $X$.

Using the backward and forward equations, it can be demonstrated that the transition density has the form:

$$
p(\Delta, y \mid x)=\Delta^{-\frac{n}{2}} \exp \left[-\frac{C^{(-1)}(x, y)}{\Delta}\right] \sum_{k=0}^{\infty} C^{(k)}(x, y) \Delta^{k}+\sum_{k=1}^{\infty} D^{(k)}(x, y) \Delta^{k} .
$$

In (4) functions $C^{(k)}(x, y)$ and $D^{(k)}(x, y)$ must be determined.

As showed in Ait-Sahalia (2006) an approximation of order $m>0$ is obtained:

$$
p^{(m)}(\Delta, y \mid x)=\Delta^{-\frac{n}{2}} \exp \left[-\frac{C^{(-1)}(x, y)}{\Delta}\right] \sum_{k=0}^{m} C^{(k)}(x, y) \Delta^{k}+\sum_{k=1}^{m} D^{(k)}(x, y) \Delta^{k} .
$$

The term $\Delta^{-\frac{n}{2}} \exp \left[-\frac{C^{(-1)}(x, y)}{\Delta}\right] \sum_{k=0}^{m} C^{(k)}(x, y) \Delta^{k}$ captures the behavior of $p(\Delta, y \mid x)$ at $y$ near $x$, and the term $\sum_{k=1}^{m} D^{(k)}(x, y) \Delta^{k}$ captures the tail behavior of $p(\Delta, y \mid x)$

From theorem 1 below, the coefficients $C^{(k)}$ and $D^{(k)}$ can be founded (Ait-Sahalia, 2006).

Theorem 1. The backward equation imposes the following restrictions, 
54 ECONOMÍA: TEORÍA Y PRÁCTICA • Nueva Época, número 34, enero-junio 2011

$$
\begin{aligned}
& \text { i. } C^{(-1)}(x, y)=\frac{1}{2}\left[\int_{x}^{y} \sigma(s)^{-1} d s\right]^{2} \\
& \text { ii. } C^{(0)}(x, y)=\frac{1}{\sqrt{2 \pi} \sigma(y)} \exp \left[\int_{x}^{y}\left(\frac{\mu(s)}{\sigma^{2}(s)}-\frac{\sigma^{\prime}(s)}{2 \sigma(s)}\right) d s\right] \\
& \text { iii. } \left.\left.C^{(k+1)}(x, y)=-\left[\int_{x}^{y} \sigma^{-1}(s) d s\right]^{-(k+1)} \times C^{k} \times\right)^{k} \cdot\left[\lambda(s)-L^{B}\right] C^{(k)}(s, y)\right] d s \\
& \quad \int_{x}^{y}\left[\operatorname { e x p } ( \int _ { s } ^ { x } ( \frac { \sigma ^ { \prime } ( u ) } { 2 \sigma ( u ) } - \frac { \mu ( u ) } { \sigma ^ { 2 } ( u ) } ) d u ) \cdot \sigma ^ { - 1 } ( s ) \cdot \left(\int_{s}^{y} \sigma^{-1}(u) d u\right.\right. \\
& \quad \text { for } k \geq 0
\end{aligned}
$$

where:

$$
L^{B}(\vartheta(\cdot, \cdot))=\sum_{i=1}^{n} \mu_{i}(x) \frac{\partial}{\partial x_{i}} \vartheta(\cdot,)+\frac{1}{2} \sum_{i=1}^{n} \sum_{j=1}^{n} v_{i j}(x) \frac{\partial^{2}}{\partial x_{i} \partial x_{j}} \vartheta(\cdot,)
$$

iv. $D^{(1)}(x, y)=\lambda(x) v(y-x)$

$$
\begin{aligned}
& \text { v. } D^{(k+1)}(x, y)=\frac{1}{1+k} \times \\
& {\left[A^{B} D^{(k)}(x, y)+\left.\sqrt{2 \pi} \lambda(x) \sum_{r=0}^{k} \frac{M_{2 r}^{1}}{(2 r) !} \frac{\partial^{2 r}}{\partial w^{2 r}} g_{k-r}(x, y, w)\right|_{w=0}\right] \text { para } k>0 .}
\end{aligned}
$$

where:

$$
\begin{aligned}
& g_{k}(x, y, w) \equiv C^{(k)}\left(w_{B}^{-1}(w), y\right) \cdot v\left(w_{B}^{-1}(w)-x\right) \cdot \sigma\left(w_{B}^{-1}(w)\right), \quad \text { and } \\
& M_{2 r}^{1} \equiv \frac{1}{\sqrt{2 \pi}} \int_{\Re} \exp \left(-\frac{s^{2}}{2}\right) s^{2 r} d s \quad \mathrm{y} \quad w_{B}(x, y)=\int_{y}^{x} \sigma(s)^{-1} d s
\end{aligned}
$$

And: 
Theorem 2. The forward equation imposes the following restrictions:

i. $C^{(-1)}(x, y)=\frac{1}{2}\left[\int_{x}^{y} \sigma(s)^{-1} d s\right]^{2}$

ii. $C^{(0)}(x, y)=\frac{1}{\sqrt{2 \pi} \sigma(y)} \exp \left[\int_{x}^{y}\left(\frac{\mu(s)}{\sigma^{2}(s)}-\frac{3 \sigma^{\prime}(s)}{2 \sigma(s)}\right) d s\right]$

iii. $C^{(k+1)}(x, y)=-\left[\int_{x}^{y} \sigma^{-1}(s) d s\right]^{-(k+1)} \times$

$\int_{x}^{y}\left[\exp \left(\int_{s}^{x}\left(\frac{3 \sigma^{\prime}(u)}{2 \sigma(u)}-\frac{\mu(u)}{\sigma^{2}(u)}\right) d u\right) \cdot \sigma^{-1}(s) \cdot\left(\int_{s}^{y} \sigma^{-1}(u) d u\right)^{k} \cdot\left[\lambda(s)-L^{F}\right] C^{(k)}(s, y)\right] d s$

for $k \geq 0$

where:

$$
L^{F}(\vartheta(\cdot,))=-\sum_{i=1}^{n} \frac{\partial}{\partial x_{i}}\left[\mu_{i}(x) \vartheta(\cdot,)\right]+\frac{1}{2} \sum_{i=1}^{n} \sum_{j=1}^{n} \frac{\partial^{2}}{\partial x_{i} \partial x_{j}}\left[v_{i j}(x) \vartheta(\cdot,)\right]
$$

iv. $D^{(1)}(x, y)=\lambda(x) v(y-x)$

$$
\begin{aligned}
& D^{(k+1)}(x, y)=\frac{1}{1+k} \times \\
\text { v. } & {\left[A^{B} D^{(k)}(x, y)+\sqrt{2 \pi} \sum_{r=0}^{k} \frac{M_{2 r}^{1}}{(2 r) !} \frac{\partial^{2 r}}{\partial w^{2 r}}\left[\lambda\left(w_{F}^{-1}(w)\right) h_{k-r}(x, y, w)\right]_{w=0}\right] }
\end{aligned}
$$

where for $k>0$

$$
\begin{aligned}
& h_{k}(x, y, w) \equiv C^{(k)}\left(x, w_{F}^{-1}(w)\right) \cdot v\left(y-w_{F}^{-1}(w)\right) \cdot \sigma\left(w_{F}^{-1}(w)\right), \text { and } \\
& M_{2 r}^{1} \equiv \frac{1}{\sqrt{2 \pi}} \int_{\Re} \exp \left(-\frac{s^{2}}{2}\right) s^{2 r} d s \quad \text { and } \quad w_{F}(x, y)=\int_{x}^{y} \sigma(s)^{-1} d s .
\end{aligned}
$$

Theorem 1 and Theorem 2, given a set of constraints on the equations and "backward" and "forward" Kolmogorov, along with conditions 1 and 2 are used to solve the approximate transition density. 
Returning to the parametric models of interest rates and making the appropriate calculations were obtained transition density functions for each of them, are in Table 3. Furthermore it is assumed that the size of the jump $J_{t}$ is normal and i.i.d. with mean $\mu_{S}$ and variance $\sigma_{S}^{2}$.

Table 3

\begin{tabular}{|c|c|}
\hline $\begin{array}{l}\text { Parametric } \\
\text { Model }\end{array}$ & $\begin{array}{l}\text { Transition density function } \\
\qquad p(\Delta, y \mid x)\end{array}$ \\
\hline $\begin{array}{l}\text { Vasicek } \\
\text { (1977) }\end{array}$ & 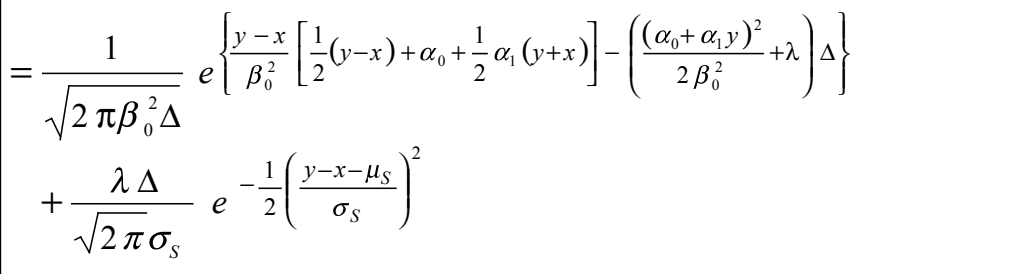 \\
\hline $\begin{array}{l}\text { CIR (Cox, } \\
\text { Ingersoll y } \\
\text { Ross, 1985) }\end{array}$ & $\begin{aligned}= & \frac{1}{\sqrt{2 \pi \Delta} \beta_{1}}\left(\frac{y}{x}\right)^{-\frac{\alpha_{0}}{\beta_{1}^{2}}} e^{\left\{\frac{-2}{2 \beta_{1}^{2} \Delta}(\sqrt{y}-\sqrt{x})^{2}+(y-x)\left(\frac{\alpha_{1}}{2 \beta_{1}^{2}}-\frac{3}{4}\right)-\left(\frac{\left(\alpha_{0}+\alpha_{1} y\right)^{2}}{2 \beta_{2}^{2} y}+\lambda\right) \Delta\right\}} \\
& +\frac{\lambda \Delta}{\sqrt{2 \pi} \sigma_{S}} e^{-\frac{1}{2}\left(\frac{y-x-\mu_{S}}{\sigma_{S}}\right)^{2}}\end{aligned}$ \\
\hline CIR VR & $\begin{aligned}= & \frac{1}{\sqrt{2 \pi \Delta x^{3}} \beta_{1}}\left(\frac{y}{x}\right)^{-\frac{9}{4}} e^{\left\{\frac{1}{\beta_{1}^{2} \Delta}\left(\frac{1}{\sqrt{y}}-\frac{1}{\sqrt{x}}\right)^{2}+\lambda \Delta\right\}} \\
& +\frac{\lambda \Delta}{\sqrt{2 \pi} \sigma_{S}} e^{-\frac{1}{2}\left(\frac{y-x-\mu_{S}}{\sigma_{S}}\right)^{2}}\end{aligned}$ \\
\hline $\begin{array}{l}\text { Brennan \& } \\
\text { Schwartz } \\
(1982)\end{array}$ & $\begin{aligned}= & \frac{1}{\sqrt{2 \pi \Delta} \beta_{2} x^{2}}\left(\frac{y}{x}\right)^{-\frac{3}{2}} e^{\left\{\frac{\alpha_{0}}{3 \beta_{2}^{2}}\left[\frac{1}{x^{3}}-\frac{1}{y^{3}}\right]+\frac{\alpha 1}{2 \beta_{2}^{2}}\left[\frac{1}{x^{2}}-\frac{1}{y^{2}}\right]-\frac{1}{2 \Delta \beta_{2}^{2}}\left[\frac{1}{x}-\frac{1}{y}\right]-\left(\frac{\left(\alpha_{0}+\alpha_{1} y\right)^{2}}{2 \beta_{1}^{2}}+\lambda\right) \Delta\right\}} \\
& +\frac{\lambda \Delta}{\sqrt{2 \pi} \sigma_{S}} e^{-\frac{1}{2}\left(\frac{y-x-\mu_{S}}{\sigma_{S}}\right)^{2}}\end{aligned}$ \\
\hline Chan (1992) & $\begin{aligned}= & \frac{1}{\sqrt{2 \pi \Delta} \beta_{2} x^{\beta_{3}-1}}\left(\frac{y}{x}\right)^{-\frac{3}{2} \beta_{3}} e^{\left\{\frac{x^{\beta_{3}-1}-y^{\beta_{2}-1}}{2 \beta_{2}^{2}\left(1-\beta_{3}\right) \Delta}+\frac{\alpha_{0}\left(y^{1-2 \beta_{3}}-x^{1-2 \beta_{3}}\right)}{\beta_{2}^{2}\left(1-2 \beta_{3}\right)}+\frac{\alpha_{1}\left(y^{2 \beta_{3}}-x^{2 \beta_{3}}\right)}{2 \beta_{2}^{2} \beta_{3}}-\left(\frac{\left(\alpha_{0}+\alpha_{1} y\right)^{2}}{2 \beta_{2}^{2} y^{2 \beta_{3}}}+\lambda\right) \Delta\right.} \\
& +\frac{\lambda \Delta}{\sqrt{2 \pi} \sigma_{S}} e^{-\frac{1}{2}\left(\frac{y-x-\mu_{S}}{\sigma_{S}}\right)^{2}}\end{aligned}$ \\
\hline
\end{tabular}


Table 3 (continue)

\begin{tabular}{|c|c|}
\hline $\begin{array}{l}\text { Parametric } \\
\text { Model }\end{array}$ & $\begin{array}{l}\text { Transition density function } \\
\qquad p(\Delta, y \mid x)\end{array}$ \\
\hline Merton & 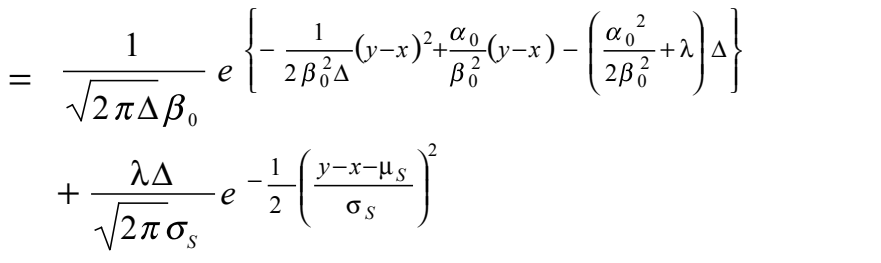 \\
\hline Dothan & $\begin{aligned}= & \frac{1}{\sqrt{2 \pi \Delta} \beta_{1} x}\left(\frac{y}{x}\right)-\frac{3}{2} e^{\left\{-\frac{1}{2 \beta_{1}^{2} \Delta}\left(\ln \frac{y}{x}\right)^{2}-\lambda \Delta\right\}} \\
& +\frac{\lambda \Delta}{\sqrt{2 \pi \sigma_{S}}} e^{-\frac{1}{2}\left(\frac{2 y-x-\mu_{S}}{\sigma_{S}}\right)}\end{aligned}$ \\
\hline $\begin{array}{l}\text { Geometric } \\
\text { Brownian } \\
\text { Motion } \\
\text { (GBM) }\end{array}$ & $\begin{aligned}= & \frac{1}{\sqrt{2 \pi \Delta} \beta_{1} x}\left(\frac{y}{x}\right) \frac{\alpha_{1}}{\beta_{1}^{2}}-\frac{3}{2} e\left\{\frac{1}{2 \beta_{1}^{2} \Delta}\left(\ln \frac{y}{x}\right)^{2}-\left(\frac{\alpha_{1}^{2}}{\beta_{1}^{2}}+\lambda\right) \Delta\right\} \\
& +\frac{\lambda \Delta}{\sqrt{2 \pi} \sigma_{S}} e^{-\frac{1}{2}\left(\frac{y-x-\mu_{S}}{\sigma_{S}}\right)^{2}}\end{aligned}$ \\
\hline $\begin{array}{l}\text { Constant } \\
\text { Elasticity } \\
\text { Variance } \\
\text { (CEV) }\end{array}$ & $\begin{array}{l}=\frac{1}{\sqrt{2 \pi \Delta \beta_{1} x}} \gamma\left(\frac{y}{x}\right)-\frac{3}{2} \gamma\left\{\frac{\left(y^{1-\gamma}-x^{1-\gamma^{2}}\right)}{2 \beta_{1}^{2}(1-\gamma)^{2} \Delta}+\frac{\alpha_{1}}{2 \beta_{1}^{2} \gamma}\left(y^{2 \gamma}-x^{2} \gamma\right)-\left(\frac{\alpha_{1}^{2}}{2 \beta_{2}^{2} x^{2 \gamma-1}}+\lambda\right) \Delta\right. \\
\quad+\frac{\lambda \Delta}{\sqrt{2 \pi} \sigma_{S}} e^{-\frac{1}{2}\left(\frac{y-x-\mu_{S}^{2}}{\sigma_{S}}\right)}\end{array}$ \\
\hline
\end{tabular}

\section{ANALYSIS FOR THE SPOT EXCHANGE RATE PESO-DOLLAR}

The data used to form the marginal density estimators consist of discrete observations (daily) exchange rate peso-dollar. The parameters of this process in discrete time are estimated using the technique of generalized method of moments. Thus, the data are used to estimate the continuous density of the process. Since the size of the time period is large, the estimators have several desirable statistical property known as asymptotic properties. 
Due to market conditions, the analysis is done for two time periods. The first is to consider the time series of the exchange rate peso-dollar on 2 January 2004 until before the crisis September 2008. The second stage is to consider the period of the crisis and is considered January 2004 until February 2009.

\section{Until 12 September 2008}

For the first part, regardless of Poisson jumps, the results obtained for the nonparametric model are:

\begin{tabular}{|c|c|}
\hline Number of Data $(n)$ & 1,191 \\
\hline$\hat{E}_{M}$ & 1.70 \\
\hline$\hat{V}_{M}$ & 194.02 \\
\hline Confidence Level (95\%) & 1.64485 \\
\hline Bandwith & 0.00009 \\
\hline$c($ alfa $)=$ & 1.92116 \\
\hline
\end{tabular}

The results for parametric models:

\begin{tabular}{|c|c|c|c|c|c|}
\cline { 2 - 6 } \multicolumn{1}{c|}{} & Vasicek & CIR & $\begin{array}{c}\text { Brennan \& } \\
\text { Schwartz } \\
\mathbf{( 1 9 8 2 )}\end{array}$ & Chan & Merton \\
\hline Minimum & 47.45185 & 47.62237 & 47.62237 & 47.62237 & 47.62237 \\
\hline Statistic M & 5.31329 & 5.33238 & 5.33238 & 5.33238 & 5.33238 \\
\hline Results & REJECT & REJECT & REJECT & REJECT & REJECT \\
\hline
\end{tabular}

\begin{tabular}{|c|c|c|c|c|c|}
\cline { 2 - 6 } \multicolumn{1}{c|}{ CIR SR } & Dothan & CIR VR & GBM & CEV \\
\hline Minimum & 47.62686 & 47.62237 & 47.62237 & 47.62266 & 47.45187 \\
\hline Statistic M & 5.33288 & 5.33238 & 5.33238 & 5.33241 & 5.31329 \\
\hline Results & REJECT & REJECT & REJECT & REJECT & REJECT \\
\hline
\end{tabular}


These are the results that were obtained and as noted has rejected the null hypothesis in each of them, i.e. there is no evidence that there are parametric values for which the previous models are an acceptable representation of data:

For the second part, considering Poisson jumps, the results for the nonparametric model are:

\begin{tabular}{|c|c|}
\hline Number of Data $(n)$ & 1,191 \\
\hline$\hat{E}_{M}$ & 23.92 \\
\hline$\hat{V}_{M}$ & 418.56 \\
\hline Confidence Level (95\%) & 1.64485 \\
\hline Bandwith & 0.00004 \\
\hline$c($ alfa $)=$ & 0.00030 \\
\hline
\end{tabular}

The results for parametric models, in this case 3 models were not rejected:

\begin{tabular}{|c|c|c|c|c|}
\cline { 2 - 5 } \multicolumn{1}{c|}{} & Vasicek & $\begin{array}{c}\text { Brennan \& } \\
\text { Schwartz }\end{array}$ & Chan & Merton \\
\hline Minimum & 0.000000192997 & 0.000000170330 & 9252.656170536750 & 0.000000170868 \\
\hline Statistic M & 0.000000008296 & 0.000000007322 & 397.730648900543 & 0.000000007345 \\
\hline Results & CAN NOT REJECT & CAN NOT REJECT & CAN NOT REJECT & CAN NOT REJECT \\
\hline
\end{tabular}

\begin{tabular}{|c|c|c|c|}
\cline { 2 - 4 } \multicolumn{1}{c|}{} & CIR SR & Dothan & CIR VR \\
\hline Minimum & 0.48178 & $8,867.98608$ & 0.00084 \\
\hline Statistic M & 0.02071 & 381.19539 & 0.00004 \\
\hline Results & REJECT & REJECT & REJECT \\
\hline
\end{tabular}

Considering models with Poisson jumps is observed that three models are not rejected, which does not say that there are parametric values for which the models of Vasicek, Brennan and Merton have an acceptable representation of data.

\section{Until 20 February 2009}

For the first part, regardless of Poisson jumps, the results obtained for the nonparametric model are: 
60 ECONOMÍA: TEORÍA Y PRÁCTICA • Nueva Época, número 34, enero-junio 2011

\begin{tabular}{|c|c|}
\hline Number of Data (n) & 1,300 \\
\hline$\hat{E}_{M}$ & 0.70 \\
\hline$\hat{V}_{M}$ & 12.96 \\
\hline Confidence Level (95\%) & 1.64485 \\
\hline Bandwith & 0.00021 \\
\hline$c($ alfa $)=$ & 0.78233 \\
\hline
\end{tabular}

The results for parametric models:

\begin{tabular}{|c|c|c|c|c|c|}
\cline { 2 - 6 } \multicolumn{1}{c|}{} & Vasicek & CIR & $\begin{array}{c}\text { Brennan \& } \\
\text { Schwartz (1982) }\end{array}$ & Chan & Merton \\
\hline Minimum & 7.87259 & 7.89777 & 7.89767 & 7.89769 & 7.89776 \\
\hline Statistic M & 2.19786 & 2.20489 & 2.20486 & 2.20487 & 2.20489 \\
\hline Results & REJECT & REJECT & REJECT & REJECT & REJECT \\
\hline
\end{tabular}

\begin{tabular}{|c|c|c|c|c|c|}
\cline { 2 - 6 } \multicolumn{1}{c|}{} & CIR SR & Dothan & CIR VR & GBM & CEV \\
\hline Minimum & 7.89963 & 7.89768 & 7.89767 & 7.89923 & 7.87279 \\
\hline Statistic M & 2.20541 & 2.20486 & 2.20486 & 2.20529 & 2.19791 \\
\hline Results & REJECT & REJECT & REJECT & REJECT & REJECT \\
\hline
\end{tabular}

For the period of the crisis, these are the results that were obtained and as noted has rejected the null hypothesis in each of them, i.e. there is no evidence that there are parametric values for which the previous models are an acceptable representation of data.

For the second part, considering Poisson jumps, the results for the nonparametric model are:

\begin{tabular}{|c|c|}
\hline Number of Data $(n)$ & 1,299 \\
\hline$\hat{E}_{M}$ & 21.43 \\
\hline$\hat{V}_{M}$ & 0.32 \\
\hline Confidence Level (95\%) & 1.64485 \\
\hline Bandwith & 0.00003 \\
\hline$c($ alfa $)=$ & 0.00028 \\
\hline
\end{tabular}


The results for parametric models, in this case 4 models were not rejected:

\begin{tabular}{|c|c|c|c|c|}
\cline { 2 - 5 } \multicolumn{1}{c|}{} & Vasicek & Brennan \& Schwartz & Chan & Merton \\
\hline Minimum & 0.00000 & 0.00000 & 0.00072 & 0.00000 \\
\hline Statistic M & 0.00000 & 0.00000 & 0.00003 & 0.00000 \\
\hline Results & CAN NOT REJECT & CAN NOT REJECT & CAN NOT REJECT & CAN NOT REJECT \\
\hline
\end{tabular}

\begin{tabular}{|c|c|c|c|}
\cline { 2 - 4 } \multicolumn{1}{c|}{} & CIR SR & Dothan & CIR VR \\
\hline Minimum & 0.87275 & 0.94609 & 0.00077 \\
\hline Statistic M & 0.03965 & 0.04298 & 0.00003 \\
\hline Results & REJECT & REJECT & REJECT \\
\hline
\end{tabular}

For the period of the crisis and considering models with Poisson jumps, it is observed that 4 models are not rejected, which does not say that there are parametric values for which the models of Vasicek, Brennan, Chan and Merton have an acceptable representation of data.

\section{CONCLUSIONS}

We show that the continuous-time models with Poisson jumps can give an acceptable representation of data, in this case the dollar peso exchange rate. However, this result was also observed in Núñez (2007) applied to the interest rate in Mexico.

\section{REFERENCES}

Ait-Sahalia, Y. (1992a), "The Delta and Boostrap Methds for Nonlinear Kernel Funtionals", Working Paper, University of Chicago.

(1996a), "Testing Continuous-Time Models of the Spot Interest Rate", The Review of Financial Studies, Vol. 9, No. 2, pp. 385-426.

- (1996b), "Nonparametric Pricing of Interest Rate Derivative Securities", Econometrica, Vol. 64, No. 3, pp. 527-560. 
Ait-Sahalia, Y. (1999), “Transition for Interest Rate and Other Nonlinear Diffusion”, The Journal of Finance, Vol. 54, No. 4, pp. 1361-1395.

- (2002), "Maximum Likelihood Estimation of Discretely Sampled Diffusions: A Closed Form Approximation Approach", Econometrica, 70, No. 1, pp. 223-262.

— y Fan Jianqin, Peng (2006), "Nonparametric Transition-Based Test for JumpDiffusions", Working Paper.

Andersen and Lund (1997), “A Three- Factor Model of Short Term Interest Rate”, Working Paper.

Baz, B., and Das, S. (1996), “Analytical Approximations of the Term Structure for Jump Diffusion Processes: A Numerical Analysis”, Journal of Fixed Income, pp. 78-86.

Brennan, M., and Schwatrz S. (1979), "A Continuous Time Approach to the Pricing of Bonds", Journal of Banking and Finance, Vol. 3, No. 2, pp. 25-28.

- and E. S. Schwartz (1982), "Consistent Regulatory Police under Uncertainty, Journal Economics, No. 13, pp. 506-521.

Chako (1996), "Multifactor Interest Rates Dynamics and Their Implications for Bond Pricing”, Journal of Finance, 47, pp. 1209-1227.

Chan, K.C., Karolyi, G. A., Lonstaff, F. A. and Sanders, A. B. (1992 a), “An Empirical Comparison of Alternative Models of the Short Term Interest Rate", Journal of Finance, 47, pp. 1209-1227.

- y Karolyi Andrew (1992 b), “An Empirical Comparison of Alternative models of the Short-Term Interest Rate”, Journal of Finance, Vol. 47.

Courtadon, G. (1982), "The Pricing of Options on Default-Free Bonds", Journal of Financial and Quantitative Analysis, No. 17, pp. 75-100.

Cox, J.C., Ingersoll, J.E., and Ross, S.A. (1985), "A Theory of the Term Structure of Interest Rates", Econometrica, Vol. 53, pp. 363-407.

Das, S. (1998), "Poisson Gaussian Process and the Bond Markets", NBER, Working Paper Series, No. 6631.

- (1999), "Mean Rate Shifts and Alternative Models of the Interest Rate: Theory and Evidence", Working Paper, New York University.

Dothan, Uri (1978), "On the Term Structure of interest Rates”, Journal of Financial Economics, Vol. 6.

Floyd B. Hanson (2006), “Applied Stochastic Processes and Control for Jump-Diffusions: Modeling, Analysis and Computation", University of Illinois, Chicago.

Gardiner, C. W. (1985), "Handbook of Stochastic Methods: For Physics, Chemistry and the Natural Sciences", Springer.

Hansen, L. P. (1982), “Large Sample Properties of Generalized Method of Moments Estimators", Econometrica, No. 50, pp. 1029-1054. 
Hong, Y. (2005), "Nonparametric Specification Testing for Continuous-Time Models with Applications to term Structure of Interest Rates", Review of Finanacial Studies, No. 18.

Huang, Chi-Fy (1985), "Information Structure and Equilibrium Asset Pricing”, Journal of Economic Theory, No. 35, pp. 33-71.

Jarrow, R. and Turnbull, S. M. (1995), "Pricing Derivatives on Financial Securities Subject to Credit Risk", The Journal of Finance, Vol. 50, No. 1, 5, pp. 3-86.

Jiang, G. (1998), "Nonparametric modeling of U.S. Interest Rate Term Structure Dynamics and Implications on the Prices of Derivative Securities", Journal of Financial and Quantitative Analysis, Vol. 33, No. 4, pp. 465-497.

Jilian Yu (2005), "Closed Form likelihood Estimation of Jump-Diffusions with an Application to the Realignmetn Risk", Journal of Finance, Vol. 58.

Johannes, M. (2004), "The Statistical and Economic Role of Jumps in Continuous Time Interest Rate Models", The Journal of Finance, LIX, 1, pp. 227-260

Karlin and Taylor (1981), A Second Course in Stochastic Processes, Academic Press, New York.

Merton, R. C. (1973), “A Dynamic General Equilibrium Model of the Asset Market and its Application to the Pricing of the Capital Structure of the Firm", Working Paper, Cambridge.

Núñez, J. A., De la Cruz, J. L. and Ortega, E. (2007), “Continuous Time Models of Interest Rate: Testing the Mexican Data (1998-2006)”, Economics Bulletin, Vol. 7 , No.11, pp. 1-9.

Pritsker, Matt (1998), "Non Parametric Density Estimation and Tests of Continuous Time Interest Rate Models", Review of Financial Studies, Vol. 11, No. 3.

Protter, Philip (2005), "Stochastic Integration and Differential Equations", Springer.

Schönbucher, P. (2003), Models, Pricing and Implementation, Wiley Editions.

Segundo, Alejandro (2002), "Valuación de deuda con riesgo", tesis doctoral, ITESM, Mexico.

Vasicek, O. (1977), “An Equilibrium Characterization of the Term Structure”, Journal of Financial Economics, Vol. 5, No. 2, pp. 177-188.

Yu, J. (2007), "Closed-Form Likelihood Approximation and Estimation of Jump diffusions with Application to the Realignment Risk Premium of the Chinese Yuan", Journal of Econometrics, 141, pp. 1245-1280. 